\title{
EFEITO AGUDO DE DIFERENTES TREINAMENTO INTERMITENTE DE ALTA INTENSIDADE NOS ÍNDICES NEUROMUSCULARES
}

\author{
F. J. Arantes*, P. F. Vieira*, D.L. Borges*, J.E.D. Nunes*, A.A. Pereira* \\ *Universidade Federal de Uberlândia, Uberlândia, Brasil \\ e-mail: franciel_arantes@hotmail.com
}

Resumo: O objetivo do presente estudo foi verificar a funcionalidade do sistema neuromuscular em diferentes protocolos intermitentes de alta intensidade na corrida. Dez atletas amadores realizaram dois protocolos intermitentes (números máximos de esforços de 40 segundos com 40 segundos de recuperação e números máximos de esforços de 30 segundos com 30 segundos de recuperação) á $110 \%$ da velocidade pico. Antecedendo e pós cinco e dez minutos de cada protocolo, análises da contração isométrica voluntária máxima (CIVM) com registros simultâneos da atividade eletromiográfica (RMS) das musculaturas do vasto lateral e medial e reto femoral, foram realizadas na perna direita de cada voluntário. Entre os momentos foi possível notar diferença significativa entre os momentos pré e pós cinco e dez em ambos protocolos $(\mathrm{p}<0.05)$. Assim, como o RMS das musculaturas investigadas $(p<0.05)$. Por vez, não foram encontradas diferenças significativas entre os protocolos em nenhum desses índices $(p>0.05)$. Em consideração final, o presente estudo demonstrou não haver diferença entre protocolos intermitentes de alta intensidade nos índices de funcionalidade do sistema neuromuscular, mesmo com tempos de exaustão distintos.

Palavras-chave: Eletromiográfia, Força, Intervalado

\begin{abstract}
The aim of this study was to verify the functionality of the neuromuscular system in different protocols intermittent high intensity in the running. Ten amateur athletes performed two intermittent protocols (40 seconds maximum number of efforts with 40 seconds of recovery and maximum numbers of 30 seconds to 30 seconds efforts recovery) will $110 \%$ of peak speed. Prior and after five and ten minutes of each protocol, analysis of maximum voluntary isometric contraction (MVIC) with simultaneous recordings of electromyographic activity (RMS) of the musculature of the lateral and medial rectus femoris and large, were held in the right leg of each volunteer. Among the moments it was possible to note a significant difference between pre and post five ten in both protocols ( $p$ $<0.05)$. Thus, as the RMS of the musculature investigated $(p<0.05)$. For once, there were no significant differences between the protocols in any of these indexes ( $p>0.05)$. In final consideration, this study showed no difference between high intensity intermittent protocols in the neuromuscular system functionality indices, even with different exhaust times.
\end{abstract}

\section{Keywords: Electromyography, Strength, Interval INTRODUÇÃO}

$\mathrm{O}$ treinamento intermitente de alta intensidade (TIAI) é definido de forma didática, por séries repetidas curtas ( $\leq 60$ segundos) de esforços em alta intensidade, alternada por períodos de recuperação envolvendo atividades passivas (sem esforço) ou ativas (com esforço leve) [1]. Relatos propõem que o TIAI deva ser utilizado, especialmente, em corredores de meio-fundo (800, 1.500 e 3.000 metros) e fundo (5.000 até 10.000), principalmente, porque a última volta da prova dos 10.000 metros é realizada em menos de um minuto, acima de $24 \mathrm{~km} . \mathrm{h}^{-1}$ bem acima da velocidade onde o consumo máximo de oxigênio é atingido [2, 3]. Assim, parece viável que competidores e técnicos planejem e prescrevam dentro de um período de tempo, esse método de treinamento visando à melhora do desempenho.

Tendo em vista que o TIAI causa uma série de estresse no sistema muscular, o que inclui alterações associadas ao desempenho desenvolvido pelas tensões nos músculos locomotores, recrutamento de fibras musculares e alterações na capacidade de gerar força, expandir o conhecimento a cerca do protocolo, poderá elucidar a técnicos e atletas o comportamento da funcionalidade neuromuscular da sessão de treinamento [4]. Ademais, em uma perspectiva prática, treinadores de atletas de meio fundo e/ou fundo, em muitas vezes, procuram aumentar o estresse neuromuscular da sessão do TIAI a fim de treinar o atleta a resistir à fadiga na expectativa de melhorar a economia de corrida $[5,6]$, porém, muitas vezes, o conhecimento fiel desse estresse neuromuscular provocado pela sessão é nulo.

Nesta perspectiva, informações do sistema neuromuscular podem ser extraídas da atividade eletromiográfica. Do ponto de vista fisiológico, a eletromiografia compreende a somatória dos potencias de ação emanada pelas unidades motoras, detectados por elétrodos colocados sobre a pele que recobre o músculo. A informação extraída a partir do registro do sinal eletromiográfico é considerada como uma medida global da atividade da unidade motora [7, 8].

Apesar dos fatos levantados, surpreendentemente, estudos intermitentes de alta intensidade de curta duração ( $\leq 60$ segundos). Na literatura consultada, estudos com avaliações da funcionalidade do sistema neuromuscular, estão em grande volume envolvido com corrida de forma contínua com grandes distâncias 
[30.000 á 42.195 metros] [9-11], ou em curta distância [100, 200, 400 ou 5.000 metros] [12, 13]. Assim, o objetivo do presente estudo foi verificar a funcionalidade do sistema neuromuscular em dois diferentes protocolos de treinamento intermitente de alta intensidade em corredores amadores.

\section{MATERIAIS E MÉTODOS}

\section{Sujeitos}

A amostra foi composta por dez homens habituados a treinos e eventos de corrida de rua, sendo recrutados de forma intencional não-probalistica por conveniência, considerados saudáveis após exame clínico (PAR-Q). Este estudo foi aprovado pelo Comitê de Ética da Universidade Federal de Uberlândia com o número $974.358 / 2015$.

\section{Delineamento do estudo}

A primeira visita, os voluntários realizam um teste incremental até a exaustão em esteira para determinação da velocidade pico. Nas visitas subsequentes (dois e três), foram empregadas para analises neuromusculares dos dois TIAI investigadas no estudo.

\section{Teste incremental}

O protocolo foi realizado em uma esteira ergométrica motorizada (Movement modelo E-740 Brasil), com cargas progressivas (velocidade) até a exaustão.

Após três minutos de aquecimento a $6 \mathrm{~km} \cdot \mathrm{h}^{-1}$, o protocolo incremental teve inicio com velocidade inicial da esteira a $9 \mathrm{~km}^{-1}$ com incremento de $1 \mathrm{~km}^{-1}$ a cada dois minutos com 30 segundos de intervalo passivo entre os incrementos [14]. As condições da sala foram controladas em todas as avaliações (temperatura (22-24 ${ }^{\circ} \mathrm{C}$ ) e umidade (50-60\%)).

\section{Determinação da velocidade pico ( $V$ pico)}

A velocidade pico ( $\mathrm{V}_{\text {pico }}$ ) do teste incremental foi calculada com base na velocidade referente ao último estágio completo. Ajustes foram aplicados segundo recomendações de Kuipers, Verstappen [15], onde:

$\mathrm{V}_{\text {pico }}=\mathrm{V}_{\text {completo }}+\mathrm{t} / \mathrm{T} *$ incremento da velocidade

Em que, $\mathrm{V}_{\text {completo }}$ é a velocidade $(\mathrm{km})$ completo no último estágio; t é o tempo (segundos) sustentado durante o estágio incompleto; $\mathrm{T}$ é o tempo total (segundos) estabelecido para o estágio completo (120 segundos) e incremento da velocidade é a velocidade incrementada a cada estágio $(1 \mathrm{~km})$.

\section{Protocolo intermitente de alta intensidade}

Os voluntários foram indicados a não praticar nenhum exercício extenuante nas últimas 24 horas antecedendo aos testes, comparecerem no laboratório no mesmo horário da primeira visita (teste incremental), estar com vestimenta adequada e em condições alimentados e hidratados. Os testes foram realizados em duas semanas com intervalo de 72 a 96 horas entre eles.

Precedendo os testes intermitentes, em um período de cinco minutos a $65 \%$ da $\mathrm{V}_{\text {pico }}$ alcançado no teste incremental, os voluntários realizaram um aquecimento contando ainda com duas séries de cinco segundos com 30 segundos de intervalo entre os mesmos, á $100 \%$ da V pico. Realizado o aquecimento, após três minutos, o teste teve início.

Os protocolos intermitentes consistiam em realizar períodos de esforços alternados por períodos de recuperações passivas até a exaustão máxima. Para o protocolo de esforço 40:40, os sujeitos realizaram números máximos de esforços de 40 segundos com 40 segundos de recuperação, sendo a relação de E:R de 1:1. Para o protocolo de esforço 30:30, os sujeitos realizaram números máximos de esforços de 30 segundos com 30 segundos de recuperação, sendo a relação de E:R de 1:1.

\section{Avaliações neuromusculares}

Durante o período experimental, a Funcionalidade do Sistema Neuromuscular (FSN) (curva força-tempo isométrica (Cf-t) e atividade eletromiográfica (RMS)) foram avaliadas em diferentes momentos dos protocolos.

Em cada uma das condições experimentais (diferentes sessões dos protocolos) foi iniciada com dois registros da CIVM e atividade RMS simultaneamente, com intervalo de recuperação de 120 segundos entre os registros. Os maiores valores foram adotados para as comparações com os demais momentos. Duas novas CIVM foram realizadas nos minutos cinco e dez após o período experimental

\section{Avaliação da curva força-tempo}

O esforço isométrico máximo, de extensão unilateral de joelho direito, foi avaliada por meio de uma cadeira extensora modelo Flexor-Extensor (Axcess Fitness). Foi acoplada a cadeira, por meio de um sistema de correntes um transdutor de força (modelo $5000 \mathrm{~N}$, EMG System ${ }^{\mathrm{TM}}$, São José dos Campos, SP, Brasil). Previamente a avaliação, o transdutor de força foi calibrado seguindo recomendações do fabricante.

O participante foi posicionado sobre o assento do equipamento com o joelho flexionado a $90^{\circ}$, semelhante ao descrito por Billaut, Basset [16], com a posição aferida por um goniômetro manual (Carci, Brasil). Nos momentos de avaliação os voluntários foram instruídos a realizar suas CIVM "tão rápido quanto possível" por seis segundos, sem retirar o quadril do acento com as mãos posicionadas na região exata de apoio. A aquisição do sinal proveniente do transdutor de força foi realizada por meio de um eletromiógrafo (modelo MyosystemBr1 P80, DataHominis Tecnologia Ltda., Uberlândia, MG, Brasil). O início da produção de força muscular foi definido como o ponto na qual o valor de força muscular excedeu $7.5 \mathrm{~N}$ acima da linha de base [17]. A CIVM foi determinada como o mais alto valor registrado dentro da janela de um segundo.

\section{Atividade eletromiográfica}

O registro do sinal da atividade eletromiográfica, foi realizado por meio de um eletromiógrafo 
(MyosystemBr1 P80, DataHominis Tecnologia Ltda., Uberlândia, MG, Brasil). Os sinais foram coletados usando o software do próprio eletromiógrafo (MyosystemBr1 (versão 3.5.6))

\section{Preparação da pele e posição dos eletrodos}

A preparação do voluntário consistiu em tricotomia e limpeza da pele com álcool $70 \%$. Com o auxílio de fita adesiva microporosa, os eletrodos foram posicionados sobre os músculos vasto lateral (VL), reto femoral (RF) e vasto medial (VM), precisamente na linha média do ventre muscular, com superfície de detecção perpendicular à direção das fibras musculares; o eletrodo de referência foi posicionado sobre a cabeça da ulna e untado com pasta gel eletrocondutora. A colocação dos eletrodos foi realizada considerando a especificidade biotípica de cada indivíduo e de acordo com as recomendações européias para eletromiografia de superfície (SENIAM) [18]. Manobras específicas de CIVM foram realizadas para garantir a exata localização dos músculos, a fim de facilitar a colocação do eletrodo.

\section{Captação do sinal, marcação e recolocação dos eletrodos}

A atividade eletromiográfica foi captada por meio de eletrodos de superfície ativo diferenciais simples (DataHomis Tecnologia Ltda., Uberlândia, MG, Brasil), composto por duas barras retangulares paralelas de prata (10 $\mathrm{mm}$ de comprimento x $1 \mathrm{~mm}$ de largura) e distanciadas $10 \mathrm{~mm}$ entre si, ajustados com ganho de 20 vezes para cada canal dos eletrodos, com taxa de amostragem de $4000 \mathrm{~Hz}$ por canal. O posicionamento de cada eletrodo foi cuidadosamente marcado com caneta esferográfica (Faber-Castell, Ponta Porosa, Soft Point) sobre a pele na tentativa de assegurar a recolocação dos eletrodos nos mesmos locais para os diferentes momentos (antes e depois) e dias de avaliações. Ainda para assegurar o recolocamento dos eletrodos no mesmo local em diferentes dias, supondo que a tinta da caneta esferográfica apagasse, mapas locais da perna avaliada foram devidamente registrados em transparência (papel acetato), técnica considerada como a melhor para registro em diferentes dias de avaliações [19].

\section{Root mean square (RMS)}

$\mathrm{O}$ sinal eletromiográfico bruto referente a um segundo (1 segundo), o mesmo utilizado para definir a CIVM, foi filtrado com um filtro Butterworth de segunda ordem e frequência de $20 \mathrm{~Hz}$. Assim, por meio da raiz quadrática da média, o valor de Root Mean Square (RMS) foi obtido.

\section{Análise estatística}

Todas as variáveis estão apresentadas como média \pm erro padrão da média. Para verificar a normalidade dos dados, foi utilizado o teste de Shapiro-Wilk. Para comparações entre os protocolos foi empregado o teste $t$ pareado. Nos diferentes momentos foi empregado o teste de variância (ANOVA) com medidas repetidas com teste de post-hoc de Turkey quando encontrado interação entre alguma variável. Em todo processamento foi adotado nível de significância de 5\%. Todos os procedimentos estatísticos foram realizados no pacote computadorizado GraphPad Software Inc., San Diego, CA, EUA versão 6.0

\section{RESULTADOS}

Os voluntários tinham idade, estatura, massa corporal índice de massa corporal, gordura corporal, quantidade de treinos semanais e experiência de 25,45 \pm 1,25 anos, $174 \pm 0,03 \mathrm{~cm}, 64,91 \pm 2,48 \mathrm{~kg}, 21,47 \pm 0,46$ $\mathrm{kg} / \mathrm{m}^{2}, 7,09 \pm 0,62 \%, 6 \pm 0,42$ dias e $7 \pm 1,36$ anos, respectivamente.

O tempo em exercício para o protolocos foram significativamente diferentes $(40: 40 \quad[1082.8 \pm 59.78$ segundos] e 30:30 [1445.8 \pm 85.42 segundos $] \mathrm{p}=0.01$ ).

\section{CIVM em diferentes momentos e protocolos.}

Valores de CIVM estão apresentados na figura 1. Os dados foram normalizados referentes ao pré, considerado como $100 \%$, as reduções dos momentos posteriores (5 e 10 minutos) foram expressos em valores percentuais referidos a ele. Nos painéis A e B estão apresentadas as reduções da CIVM dos protocolos 40:40 e 30:30 respectivamente nos diferentes momentos. Em todos os protocolos houve reduções significativas dos momentos pós 5 e 10 minutos referentes ao pré. $\mathrm{O}$ teste $\mathrm{t}$ pareado não apontou diferença entre as diferenças percentuais nos momentos pós 5 e 10 minutos $(p>0.05)$
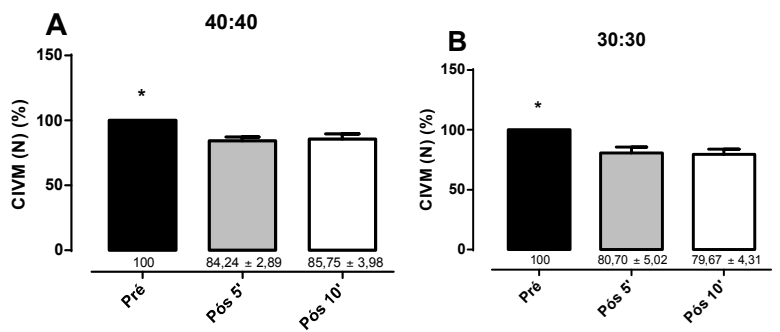

Resposta da CIVM avaliadas em momentos pré, pós 5 e pós 10 minutos dos TIAI. * = Diferença significativa dos momentos pós 5 e pós 10 minutos $(\mathrm{p}<0.05)$.

Na tabela 2 estão expressos os valores de RMS entre os momentos. Com exceção do músculo VM no protocolo 30:30, todos os outros comportaram-se da mesma forma, com reduções entre o momento pré e os momentos posteriores. Assim, como os índices de força, os protocolos não apresentaram diferença estatística entre os protocolos $(\mathrm{p}>0.05)$

Tabela 1 - Informações eletromiográfica

\begin{tabular}{lccc}
\hline & \multicolumn{3}{c}{$\mathbf{4 0 : 4 0}$} \\
\cline { 2 - 4 } RMS_VL (\%) & $100 *$ & $74,77 \pm 6,27{ }^{\Delta}$ & $69,66 \pm 6,39$ \\
RMS_RF (\%) & $100 *$ & $75,95 \pm 6,65$ & $74,09 \pm 6,61$ \\
RMS_VM (\%) & $100 *$ & $62,44 \pm 8,18$ & $59,02 \pm 6,03$ \\
\hline & \multicolumn{3}{c}{$\mathbf{3 0 : 3 0}$} \\
\cline { 2 - 4 } & Pré & Pós 5' & Pós 10' \\
RMS_VL (\%) & $100 *$ & $71,03 \pm 8,00$ & $63,58 \pm 7,47$
\end{tabular}


\begin{tabular}{llll} 
RMS_RF (\%) & $100 *$ & $75,31 \pm 6,57$ & $65,65 \pm 6,96$ \\
RMS VM (\%) & $100^{\star}$ & $81,61 \pm 9,57$ & $68,90 \pm 5,93$ \\
\hline
\end{tabular}

$*=$ Diferença significativa dos momentos pós $(\mathrm{p}<$ $0.05)$.

$\Delta=$ Diferença significativa do momento pós $10^{\prime}(\mathrm{p}<$ $0.05)$.

\section{DISCUSSÃO}

Os principais resultados encontrados no estudo são que mesmo que os protocolos sejam diferidos do volume de esforço: recuperação, e tempo de exercício a FSN comportam-se de forma análoga.

Esses achados remetem a válidas informações ao que concerne a prescrição do treinamento de atletas. Quando treinadores ou atletas almejarem o estresse neuromuscular, qualquer um dos protocolos mencionados nesse estudo estará de acordo ou atenderá ao esperado.

Outro ponto relevante e que o protocolo 40:40 causa maiores estresse neuromuscular (queda da CIVM) em menor tempo de exercício o que pode ser uma estratégia valida para otimizar o treinamento do atleta [20].

Em virtude dos fatos mencionados, as reduções de força e sinais eletromiográficos estão atreladas a fatores como 'distúrbio' na transmissão neuromuscular entre o sistema nervoso central e a membrana muscular (fatores centrais), além de fatores metabólicos como acumulação de íons hidrogênio $\left(\mathrm{H}^{+}\right)$e fosfato inorgânico $\left(\mathrm{P}_{\mathrm{i}}\right)$ ao qual limitam a liberação de íons cálcio $\left(\mathrm{Ca}^{+2}\right)$ diminuindo o número de pontes cruzadas (fatores periféricos) acarretando em queda no recrutamento de unidades motoras e diminuição da frequência de disparo dos motoneurônios [21, 22].

\section{CONCLUSÃO}

O presente estudo demonstrou não haver diferença entre protocolos intermitentes de alta intensidade nos índices de funcionalidade do sistema neuromuscular.

\section{Referências}

1. Seiler, s. And k.j. Hetlelid, the impact of rest duration on work intensity and rpe during interval training. Med sci sports exerc, 2005. 37(9): p. 16017.

2. Billat, 1.v., interval training for performance: a scientific and empirical practice. Special recommendations for middle- and long-distance running. Part i: aerobic interval training. Sports med, 2001. 31(1): p. 13-31.

3. Thiel, c., et al., pacing in olympic track races: competitive tactics versus best performance strategy. J sports sci, 2012. 30(11): p. 1107-15.

4. Buchheit, m. And p.b. Laursen, high-intensity interval training, solutions to the programming puzzle. Part ii: anaerobic energy, neuromuscular load and practical applications. Sports med, 2013. 43(10): p. 927-54.
5. Bonacci, j., et al., neuromuscular adaptations to training, injury and passive interventions. Sports medicine, 2012. 39(11): p. 903-921.

6. Barnes, k.r. And a.e. Kilding, strategies to improve running economy. Sports med, 2015. 45(1): p. 3756.

7. Farina, d., r. Merletti, and r.m. Enoka, the extraction of neural strategies from the surface emg. J appl physiol (1985), 2004. 96(4): p. 1486-95.

8. Konrad, p., the abc of emg. A practical introduction to kinesiological electromyography, 2005. 1.

9. Nicol, c., p.v. Komi, and p. Marconnet, fatigue effects of marathon running on neuromuscular performance. Scandinavian journal of medicine \& science in sports, 1991. 1(1): p. 18-24.

10. Petersen, k., et al., muscle mechanical characteristics in fatigue and recovery from a marathon race in highly trained runners. Eur $\mathrm{j}$ appl physiol, 2007. 101(3): p. 385-96.

11. Millet, g.y., et al., mechanisms contributing to knee extensor strength loss after prolonged running exercise. J appl physiol (1985), 2003. 94(1): p. 1938.

12. Nummela, a.t., et al., fatigue during a $5-\mathrm{km}$ running time trial. Int j sports med, 2008. 29(9): p. 738-45.

13. Tomazin, k., et al., fatigue after short (100-m), medium $(200-\mathrm{m})$ and long $(400-\mathrm{m})$ treadmill sprints. Eur j appl physiol, 2012. 112(3): p. 102736.

14. Midgley, a.w., 1.r. Mcnaughton, and s. Carroll, time at vo2max during intermittent treadmill running: test protocol dependent or methodological artefact? Int j sports med, 2007. 28(11): p. 934-9.

15. Kuipers, h., et al., variability of aerobic performance in the laboratory and its physiologic correlates. Int j sports med, 1985. 6(4): p. 197-201.

16. Billaut, f., et al., effect of high-intensity intermittent cycling sprints on neuromuscular activity. Int j sports med, 2006. 27(1): p. 25-30.

17. Aagaard, p., et al., increased rate of force development and neural drive of human skeletal muscle following resistance training. $\mathrm{J}$ appl physiol (1985), 2002. 93(4): p. 1318-26.

18. Hermens, h.j., et al., development of recommendations for semg sensors and sensor placement procedures. J electromyogr kinesiol, 2000. 10(5): p. 361-74.

19. Correa, c.s. And r.s. Pinto, utilização de diferentes técnicas para o controle do posicionamento dos eletrodos de superfície na coleta do sinal eletromiográfico. Acta brasileira do movimento humano-bmh, 2012. 2(2): p. 5-13.

20. Gibala, m.j., et al., short-term sprint interval versus traditional endurance training: similar initial adaptations in human skeletal muscle and exercise performance. J physiol, 2006. 575(pt 3): p. 901-11.

21. Lattier, g., et al., fatigue and recovery after highintensity exercise part i: neuromuscular fatigue. Int j sports med, 2004. 25(6): p. 450-6. 
22. Allen, d.g., j. Lannergren, and h. Westerblad, muscle cell function during prolonged activity: cellular mechanisms of fatigue. Exp physiol, 1995. 80(4): p. 497-527. 